\title{
QUEEN'S
UNIVERSITY
BELFAST
}

\section{Restrospective genetic monitoring of the threatened Yellow marsh saxifrage (Saxifraga hirculus) reveals genetic erosion but provides valuable information for conservation strategies}

Beatty, G. E., Reid, N., \& Provan, J. (2014). Restrospective genetic monitoring of the threatened Yellow marsh saxifrage (Saxifraga hirculus) reveals genetic erosion but provides valuable information for conservation strategies. Diversity and Distributions, 20(5), 529-537. https://doi.org/10.1111/ddi.12158

Published in:

Diversity and Distributions

Document Version:

Peer reviewed version

Queen's University Belfast - Research Portal:

Link to publication record in Queen's University Belfast Research Portal

\footnotetext{
Publisher rights

(c) 2013 John Wiley \& Sons Ltd.

This is the peer reviewed version of the following article: Beatty, G. E., Reid, N., Provan, J. (2014), Retrospective genetic monitoring of the threatened Yellow marsh saxifrage (Saxifraga hirculus) reveals genetic erosion but provides valuable insights for conservation strategies. Diversity and Distributions, 20: 529-537, which has been published in final form at doi: 10.1111/ddi.12158. This article may be used for noncommercial purposes in accordance with Wiley Terms and Conditions for Self-Archiving.

General rights

Copyright for the publications made accessible via the Queen's University Belfast Research Portal is retained by the author(s) and / or other copyright owners and it is a condition of accessing these publications that users recognise and abide by the legal requirements associated with these rights.
}

Take down policy

The Research Portal is Queen's institutional repository that provides access to Queen's research output. Every effort has been made to ensure that content in the Research Portal does not infringe any person's rights, or applicable UK laws. If you discover content in the Research Portal that you believe breaches copyright or violates any law, please contact openaccess@qub.ac.uk. 


\section{Retrospective genetic monitoring of the threatened Yellow marsh saxifrage (Saxifraga hirculus) reveals genetic} erosion but provides valuable insights for conservation strategies

Gemma E. Beatty ${ }^{1}$, Neil Reid ${ }^{2}$ and Jim Provan ${ }^{1 *}$

${ }^{1}$ School of Biological Sciences, Queen's University Belfast, 97 Lisburn Road, Belfast BT9 $7 B L$

${ }^{2}$ Quercus, School of Biological Sciences, Queen's University Belfast, 97 Lisburn Road, Belfast BT9 7BL

Correspondence: Dr Jim Provan

School of Biological Sciences,

Queen's University Belfast,

97 Lisburn Road,

Belfast BT9 7BL

E-mail: J.Provan@qub.ac.uk

Tel: $+44(0) 2890972280$

Fax: +44 (0)2890975588

Running title: Genetic erosion in a threatened plant species

Word count: $\quad 3,469$ (excluding title page, abstract, references, tables and figures) 


\section{$1 \quad$ ABSTRACT}

3 Aim Retrospective genetic monitoring, comparing genetic diversity of extant populations

4 with historical samples, can provide valuable and often unique insights into evolutionary

5 processes informing conservation strategies. The Yellow marsh saxifrage (Saxifraga

6 hirculus) is listed as 'critically endangered' in Ireland with only two extant populations. We

7 quantified genetic changes over time and identified genotypes in extant populations that

8 could be used as founders for reintroductions to sites where the species is extinct.

10 Location Ireland.

12 Methods Samples were obtained from both locations where the species is currently found,

13 including the most threatened site at the Garron Plateau, Co. Antrim, which held only 13

14 individuals during 2011. Herbarium samples covering the period from 1886 to 1957 were

15 obtained including plants from the same area as the most threatened population, as well as

16 three extinct populations. In total, 422 individuals (319 present-day and 103 historical) were

17 genotyped at six microsatellite loci. Species distribution modelling was used to identify areas

18 of potentially suitable habitat for reintroductions.

20 Results Level of phenotypic diversity within the most threatened population was

21 significantly lower in the present-day compared to historical samples but levels of observed heterozygosity and number of alleles, whilst reduced, did not differ significantly. However,

23 Bayesian Clustering Analysis suggested gradual lineage replacement over time. All three

24 measures of genetic diversity were generally lower at the most threatened population

25 compared to the more substantial extant populations in Co. Mayo. Species distribution 
26 modelling suggested that habitat at one site where the species is extinct may be suitable for

27 reintroduction.

28

29 Main conclusions The dominant genetic lineage in the most threatened population is rare

30 elsewhere, thus care needs to be taken when formulating any potential reintroduction

31 programme. Our findings highlight both the need for genetic monitoring of threatened

32 populations, but also for its swift implementation before levels of diversity become critically 33 low.

34

35 Keywords

36 Bayesian clustering analysis, microsatellites, polyploid, Saxifraga hirculus, Yellow marsh 37 saxifrage. 
Knowledge of levels and patterns of intraspecific genetic diversity represents a fundamental aspect of modern conservation biology. Researchers and policy makers are now aware of the various implications of habitat loss and population extinction on diversity below the species level. Such information is crucial in the estimation of effective and minimum viable population sizes, as well as levels of inbreeding and adaptive potential (Allendorf \& Luikart, 2007; Schwartz et al., 2007). These factors are particularly relevant in populations comprising very low numbers of individuals, and typically those in immediate need of conservation.

Whilst there have been several recent attempts to predict the potential impacts of future habitat loss and/or population extinction on species' genetic diversity (Balint et al., 2011; Beatty \& Provan, 2011; Provan \& Maggs, 2012), relatively few studies have directly quantified historical loss of diversity due to past (and ongoing) extinctions. These studies generally rely on the genetic analysis of museum or herbarium samples, and have often highlighted loss of genetic diversity in extant populations compared with their historical counterparts (reviewed in Wandeler et al., 2007 and Leonard, 2008). Such retrospective genetic monitoring can provide valuable, and often unique, insights into evolutionary processes that can inform future conservation programmes (Schwartz et al., 2007; Wandeler et al., 2007; Jackson et al., 2012).

The Yellow Marsh Saxifrage (Saxifraga hirculus) is a perennial herbaceous plant with a circumpolar distribution (Hedberg, 1992). The species originated in central Asia (Hedberg, 1992), but the sole phylogeographic study carried out to date identified Alaska as the centre

61 of genetic diversity, suggesting survival in an Alaskan / Beringian refugium during the

62 Pleistocene glaciations (Oliver et al., 2006). The species suffered dramatic declines 
63 throughout in Europe during the last ca. 200 years, primarily as a result of habitat loss,

64 principally wetlands, with remaining populations being small and widely scattered (Vittoz et

65 al., 2006). The Irish Red Data Book for Vascular Plants lists the species under the

66 International Union for the Conservation of Nature (IUCN) category of 'critically

67 endangered' (Curis \& McGough, 1988). We analysed herbarium samples spanning over 150

68 years, including extinct populations, as well as samples representing populations from the

69 only two locations where the species is currently extant, to determine if there has been loss of

70 genetic variation and to use this information to formulate species augmentation and

71 reintroduction programmes further informed by species distribution modelling, which was

72 used to identify potentially suitable habitat for any reintroductions. 
METHODS

\section{Study sites}

Only two populations of Saxifraga hirculus occur in Ireland; the most threatened population consisted of only 13 individuals at the Garron Plateau, County Antrim during 2011 whilst the other is substantially larger occurring at 13 sites (each with $c a .100-200$ individuals) near Bellacorcik, Co. Mayo. Herbarium samples show that the species occurred at much greater abundance at the Garron Plateau in the past and also occurred at another site near Rasharkin, County Antrim. Two further populations, one near Coleraine, County Derry and one near Lisclogher Co. Westmeath are now extinct.

\section{Study species}

Chromosome numbers for $S$. hirculus include $2 n=16,2 n=24$ and $2 n=32$, although all populations outside the Arctic Circle studied to date, including those in Europe, are tetraploid $(2 n=32)$. Reproduction is both sexual and asexual. Flowers are markedly protandrous, but self-compatible, and are pollinated by a wide range of insects, with different pollinators in different parts of the species' range (Olesen \& Warncke, 1989; Warncke et al., 1993). Seeds lack special adaptations for dispersal, and are generally deposited close to the parent plant (Olesen \& Warncke, 1989). Vegetative reproduction occurs via rhizomes, and is believed to

92 be an important mechanism of propagation (Olesen \& Warncke, 1990).

93

94 Sampling and DNA extraction

A total of 319 present-day samples were obtained during 2011. All 13 plants from the Garron Plateau, Co. Antrim were sampled and 306 samples were collected from all 13 sites included within the Co. Mayo population (24 individuals from each with the exception of site SHE-D, 
for which 18 individuals were analysed). The species is protected under the Wildlife Acts 1976-2010 (Ireland) and Schedule 8 of the Wildlife (Northern Ireland) Order (1985), and it was an offence to pick, uproot or destroy the plant. Consequently, a single leaf was taken

101 from each plant under Government licence. Samples were stored in silica gel for

102 transportation. A total of 103 historical samples were obtained from individual plants on

103 herbarium sheets representing both extant locations in Counties Antrim and Mayo, as well as 104 from extinct populations at Rasharkin, Co. Antrim, Coleraine, Co. Derry and Lisclogher, Co. Westmeath. The sampling regime of herbarium samples and their distribution are given in Table 1 and Figure 1 (for herbarium codes see Table S1).

DNA was extracted from all samples using the Qiagen DNeasy Plant Mini Kit, after an initial 8 min grinding at $30 \mathrm{~Hz}$ using a Retsch MM300 mixer mill. DNA was quantified visually on $1 \%$ agarose gels stained with ethidium bromide and diluted to a concentration of $50 \mathrm{ng} \mu \mathrm{l}^{-1}$ for subsequent PCR. All DNA extractions from herbarium samples were carried

111 out in a laboratory where no previous $S$. hirculus work had been performed.

\section{Microsatellite genotyping}

114 All samples were genotyped for six microsatellite markers developed for S. hirculus using the

115 ISSR cloning method outlined in Provan \& Wilson (2007). Because of difficulties associated

116 with amplifying longer fragments from herbarium samples, primers were designed to amplify

117 products of less than $c a .200 \mathrm{bp}$ (Table 2). The polyploid nature of $S$. hirculus in Ireland

118 represented a further problem in scoring allele sizes accurately where stutter bands were

119 present. Consequently, we were limited to using two trinucleotide microsatellites and two

120 tetranucleotides, which generally display minimal stuttering, and two dinucleotides with

121 relatively low stuttering. Forward primers were modified by the addition of a 19 bp M13 tail

122 (5'-CACGACGTTGTAAAACGAC-3') and reverse primers were modified by the addition 
123 of a 7 bp tail (5'-GTGTCTT-3'). PCR was carried out in a total volume of $10 \mu$ containing

124100 ng genomic DNA, 10 pmol of HEX-labelled M13 primer, 1 pmol of M13-tailed forward

125 primer, 10 pmol reverse primer, $1 \mathrm{x}$ PCR reaction buffer, $200 \mu \mathrm{M}$ each dNTP, $2.5 \mathrm{mM} \mathrm{MgCl}_{2}$

126 and 0.25 U GoTaq Flexi DNA polymerase (Promega). PCR was carried out on a MWG

127 Primus thermal cycler using the following conditions for all loci with the exception of SH-3-

128 B11: initial denaturation at $94{ }^{\circ} \mathrm{C}$ for $3 \mathrm{~min}$ followed by 10 touchdown cycles of denaturation at $94{ }^{\circ} \mathrm{C}$ for $30 \mathrm{~s}$, annealing at $68{ }^{\circ} \mathrm{C}$ for $30 \mathrm{~s}\left(-1{ }^{\circ} \mathrm{C}\right.$ per cycle), extension at $72{ }^{\circ} \mathrm{C}$ for $30 \mathrm{~s}$ followed by 30 cycles (40 for herbarium samples) of denaturation at $94{ }^{\circ} \mathrm{C}$ for $30 \mathrm{~s}$, annealing at $58{ }^{\circ} \mathrm{C}$ for $30 \mathrm{~s}$, extension at $72{ }^{\circ} \mathrm{C}$ for $30 \mathrm{~s}$ and a final extension at $72{ }^{\circ} \mathrm{C}$ for $5 \mathrm{~min}$. For

132 locus $\mathrm{SH}-3-\mathrm{B} 11$, the following conditions were used: initial denaturation at $94{ }^{\circ} \mathrm{C}$ for $3 \mathrm{~min}$

133 followed by 40 cycles (50 for herbarium samples) of denaturation at $94{ }^{\circ} \mathrm{C}$ for $30 \mathrm{~s}$, annealing at $52{ }^{\circ} \mathrm{C}$ for $30 \mathrm{~s}$, extension at $72{ }^{\circ} \mathrm{C}$ for $30 \mathrm{~s}$ and a final extension at $72{ }^{\circ} \mathrm{C}$ for $5 \mathrm{~min}$. Blank negative controls were routinely used, and approximately $25 \%$ of herbarium samples were genotyped twice to check for artifacts resulting from low DNA quality, which were not

137 observed. Genotyping was carried out on an AB3730xl capillary genotyping system. Allele

138 sizes were scored using LIZ-500 size standards and were checked by comparison with 139 previously sized control samples.

\section{Genetic analysis}

142 No chromosome counts are available for Irish S. hirculus, but the species is believed to be

143 polyploid in the majority of its non-Arctic range (Hedberg, 1992), and more than two bands

144 were observed at all six loci analysed, suggesting polyploidy. Thus, it was not possible to

145 score genotypes based on allele frequencies, and as a result we could not carry out many

146 standard population genetic analyses (e.g. calculation of allelic richness, AMOVA).

147 Consequently, the patterns of alleles observed for each locus in an individual were scored as 
148 phenotypes. Within-population phenotype diversity was estimated for samples with $N \geq 5$

149 using the total number of alleles, observed heterozygosity $\left(H_{O}\right)$, namely the proportion of

150 observed heterozygous individuals in a population, and the Gini-Simpson diversity index,

151 analogous to Nei's gene diversity, averaged over loci (Jost, 2006). Genetic clustering of

152 individuals was assessed using a Bayesian procedure implemented in the STRUCTURE

153 software package (V2.3.3; Pritchard et al., 2000), which can accommodate ambiguous

154 codominant markers for polyploid species. The program was run using no prior knowledge

155 and the admixture ancestry model. Five independent runs were carried out for each value of

$156 K$, the number of genetic clusters, up to $K=10$, since log-likelihood values reached a peak at

$157 K=8$ and decreased thereafter. Each Markov chain Monte Carlo analysis used a burn-in

158 period of 10,000 followed by a further 100,000 iterations. The most likely value for $K$ was

159 estimated using the $\Delta K$ statistic of Evanno et al. (2005) implemented in the STRUCTURE

160 HARVESTER software package (V0.6.1; Earl \& vonHoldt, 2012).

162 Species distribution modelling

163 A presence-only maximum entropy approach was used to predict landscape suitability for the

164 S. hirculus throughout Ireland, from a sample set of known occurrences and spatially explicit

165 environmental parameters. Maximum entropy has been shown to frequently outperform other

166 presence-only modelling techniques particularly at very low sample sizes (Elith \& Graham,

167 2009). Environmental parameters were described at a 500m cell resolution (Table S2). The

168 software package MAXENT was used (V3.3.3k; Philips et al., 2010). To maximise model

169 flexibility, we considered linear, quadratic, threshold and hinged functions for all

170 environmental parameters (Phillips \& Dudík, 2008). Due to the paucity of records it was not

171 possible to segregate the dataset into a training and test sets, thus only a training set was used

172 (Farren et al. 2010). Jackknife re-sampling analysis was used to determine a heuristic 
173 estimate of the relative contribution of each variable based on the performance of the global

174 model (known as the regularized gain) without the variable of interest compared to the

175 influence of that variable in isolation (derived from a univariate model only). Global model

176 performance was judged using the area under the receiver operating characteristic (ROC)

177 curve (Liu et al., 2005). Marginal response curves of the predicted probability of species

178 occurrence were graphed for each explanatory variable. A map of landscape favourability

179 was generated using ArcGIS 9.3 (ESRI, California, USA) and the $10^{\text {th }}$ percentile training

180 presence was used as the threshold. 
183 Between seven and 16 alleles were detected across the six loci analysed (average 10 alleles

184 per locus; Table 2). The total number of alleles per population with sample numbers $N \geq 5$

185 ranged from 18 (GAR-1886 population) to 32 (AGH-2011 population). Observed

186 heterozygosity $\left(H_{O}\right)$ ranged from 0.389 (RAS-1884 population) to 0.882 (SHB-2011

187 population; Table 1). Levels of phenotype diversity $(H)$ ranged from 0.387 (GAR-2011

188 population) to 0.821 (BEL-1968 population; Table 1). The extant Garron Plateau population

189 had the third lowest level of $H_{O}$, after the GAR-1955 sample, and the lowest level of $H$. Both

190 values ( 0.436 and 0.387 , respectively) were lower than those in the extant Co. Mayo

191 population, where $H_{O}$ ranged from 0.500 to $0.882($ mean $=0.730)$ and $H$ ranged from 0.512

192 to $0.808($ mean $=0.670)$. For the Garron Plateau population, the level of $H$ (calculated over

193 all individuals i.e. 24 individuals sampled across six time points vs. 13 samples from 2011)

194 was significantly higher in the herbarium samples than in the extant samples, whereas levels

195 of $H_{O}$ and average number of alleles per individual $(A)$, whilst higher for herbarium samples

196 (again calculated over all individuals), were not significantly different (Table 3).

197 The results of the Bayesian clustering analysis indicated that the most likely number of

198 genetic clusters was $K=4$, followed by $K=8$ (Figure 2). For $K=4$ genetic clusters (Figure 3,

199 top), the vast majority of plants from the Garron Plateau and the now extinct Rasharkin

200 population were predominantly associated with the cluster shown in yellow, which was

201 comparatively rare elsewhere in Ireland. The population from Co. Mayo displayed varying

202 degrees of admixture, from being almost completely dominated by a single cluster (red at

203 SHB) to being comprised of a substantial fraction of all four clusters (SHA). Assignment of

204 populations to $K=8$ clusters (Figure 3, middle and bottom) revealed some further subtle

205 genetic substructuring, particularly in the Northern Ireland populations. This shows a distinct 
temporal shift from the lineage represented by light yellow, which was initially the dominant

207 lineage at both the Garron Plateau and Rasharkin populations, to the lineage represented in

208 light blue, to the point where the light yellow lineage is now almost completely absent.

209 S. hirculus occurrence was strongly associated with landscapes dominated by bog, fen,

210 marsh and swamp typically on high altitude ( $>175 \mathrm{~m}$ above sea level) plateaus (i.e. low

211 hilliness index $)$ which experienced low maximum temperatures $\left(<15^{\circ} \mathrm{C}\right)$, high precipitation

$212(1,000-1,700 \mathrm{~mm}$ of rain annually) and low seasonality i.e. consistently cool and wet all year

213 round (Figures S1 and S2). These regions were typically negatively correlated with

214 agricultural pastures. Model performance, defined as the area under the curve or AUC =

215 0.998. The model suggested that the extent of suitable habitats for S. hirculus is limited (Fig.

216 4a). Highest suitability and the greatest extent of habitat was predicted throughout north Co.

217 Mayo (Fig. 4b). The model also suggested that less optimal habitat was found throughout the

218 Co. Antrim including the Garron Plateau (Fig. 4c). A patch of potentially suitable habitat

219 (determined using the $10^{\text {th }}$ percentile training presence $=0.692$ ) was also identified near

220 Rasharkin which may represent the site of an extinct population. The habitat at locations of

221 other now extinct populations near Coleraine, Co. Derry and Lisclogher, Co. Westmeath was predicted to have vanished. 


\section{DISCUSSION}

\section{S. hirculus genetic erosion over time}

227

Maintaining genetic variation in threatened populations, which by their nature tend to be small and/or fragmented, is one of the central tenets of conservation genetics (Allendorf \& Luikart, 2007; Schwartz et al., 2007). The retrospective genetic monitoring afforded by the comparison of a critically threatened extant population with historical samples from the same area suggests that levels of population genetic diversity of $S$. hirculus in the critically endangered Garron Plateau, Co. Antrim are not only far lower than those in the other, larger extant populations in Co. Mayo, but also appreciably lower than the average values from historical samples (pre-1958) from the same area, although there is evidence of some fluctuation in these values through time. This loss of genetic diversity has been accompanied by the replacement of one lineage identified by the Bayesian clustering analysis (shown in Figure 2, bottom, in light blue) by another (shown in light yellow), to the extent that the new lineage accounts for over $60 \%$ of the total genetic diversity. These changes are probably the result of a combination of factors, foremost among which are stochastic fluctuations in allele frequencies due to the greatly exaggerated effects of genetic drift in very small populations. These changes may also have been accompanied by a founder effect, since the Garron Plataeu population was recorded as extinct after 1920, but subsequently "refound" in 1955 (Kertland, 1956). The extinction of the population at Rasharkin, Co. Antrim at the end of the $19^{\text {th }}$ century would have contributed further to the loss of this lineage, both directly and indirectly via the cessation of possible gene flow between the two Co. Antrim populations. Nevertheless, although the levels of phenotypic diversity were significantly lower in the extant population than in the historical samples, the number of alleles was not. Given that the 
number of alleles is correlated with the ability to respond to selection, this does not appear to be as serious a concern as potential inbreeding depression.

\section{Conservation implications}

252 Although information from population genetic studies can inform best-practice conservation strategies, the long decline in S. hirculus population numbers highlights a further conservation dilemma. Numbers of recorded individuals at the Garron Plateau have fallen from 130 during 1999 to 13 during 2011 (Georgina Thurgate, pers. comm.). Despite the importance of vegetative reproduction in the spread and persistence of $S$. hirculus (Olesen \& Warncke, 1990), we detected only two potentially clonal individuals (i.e. $15 \%$ shared identical multi-locus phenotypes). Nevertheless, the extremely small number of individuals comprising the extant population at the Garron Plateau leaves it extremely vulnerable to sudden, stochastic extinction. Thus, it is clear that some sort of augmentation programme is necessary. One of the goals of conservation genetics is to ensure that the provenance of

262 individuals used for such programmes is closely aligned with the population (Lesica \&

263 Allendorf, 1999), but the Garron Plateau individuals are generally associated with a genetically distinct group that is not found at any significant level elsewhere in the remaining populations in Ireland. Re-establishment or augmentation of a population using genetically divergent individuals results in a trade-off between increasing population numbers at the risk

267 of outbreeding depression (Edmunds, 2007). The Bayesian clustering analysis suggests that if

268 a source population is required for augmentation, it should be the SHA population in Co.

269 Mayo, which not only has the highest percentage assignment to the predominant cluster

270 found in the Garron Plateau, but also contains a mixture of several different lineages. This

271 represents a further important aspect of strategic conservation based on molecular genetic

272 approaches, namely the fact that data from a low number of putatively neutral loci do not 
necessarily provide insights into the relative fitness of genotypes, particularly in differing habitats (Ennos et al. 1997; Hollingsworth et al. 1999). Augmentation or introduction of a range of genotypes, including those closest to genotypes found in the extant Garron population, as is the case for the Co. Mayo SHA population, will provide a balance between

277 "genotype matching" and sufficient variation for natural selection to operate on. Of course, reintroduction need not be limited to material from a single source population, and the results of the genetic clustering analysis could be used to identify the widest possible range of genetic diversity for reintroduction, if so desired.

S. hirculus occurrence was associated with bog, fen, marsh and swamp typically on high altitude plateaus with low maximum temperatures, high precipitation and low seasonality i.e. consistently cool and wet. The loss of the Coleraine, Co. Derry and Lisclogher, Co.

Westmeath populations could be attributed to loss of such habitat, since the species distribution model did not identify these areas as currently suitable. A number of areas in the Garron Plateau, Co. Antrim were identified as potentially suitable for establishing new populations (via ex-situ conservation) to further supplement and expand the extant population. A single area of potentially suitable habitat was identified near the site of the now extinct population at Rasharkin, Co. Antrim. Insights into the historical genetic makeup of the now extinct Rasharkin population afforded by the analysis of the herbarium samples mean that a controlled reintroduction program, based on recreating the genetic make-up of

292 the original population from individuals extant elsewhere (i.e. Co. Mayo), could maximise 293 the potential success of re-establishing this lost population.

The genetic changes revealed by the retrospective genetic monitoring indicate the need to implement such approaches as soon as possible. Regular censuses of the population at the

296 Garron Plateau began during 1999 when there were 130 plants If genetic monitoring had 297 commenced at the same time there would have been more chance of developing a successful 
298 ex-situ conservation programme to maximise genetic diversity than at present. As it is, the 299 current scenario further highlights the need for conservation practitioners to move away from

300 a 'fire-fighting' mentality (Mace and Purvis, 2008). Nevertheless, the findings of our study

301 can be used to inform any potential reintroduction / augmentation programmes. Results from

302 a previous re-establishment program in Scotland indicate that ex-situ propagation of seedlings

303 followed by transplantation is a more successful method than simply sowing seeds directly

304 onto potential recovery sites (Welch 2002). Based on the information from the current study,

305 genetic analysis of ex-situ individuals could be used to select individuals most representative

306 of the current extant gene pool, whilst aiming to maximise genetic diversity. 
310 This study was commissioned and funded by the Natural Heritage Research Partnership

311 between the Northern Ireland Environment Agency (NIEA), Department of the Environment

312 Northern Ireland and Quercus, Queen's University Belfast. We are grateful to Kyle Hunter

313 and Mark Wright (NIEA) and James Kilroy, Cameron Clothworthy, Leonard Floyd and

314 Deirdre Lynn from the National Parks \& Wildlife Service, Department of Arts, Heritage and

315 the Gaeltacht, Republic of Ireland for sample collection. Herbarium samples were provided

316 by Colin Kelleher, Noeleen Smyth and Mathew Jebb (National Botanic Garden of Ireland)

317 and Peter Crowther (Ulster Museum, National Museums Northern Ireland). We are also

318 grateful to Associate Editor Andy Lowe and two anonymous reviewers for constructive

319 comments that greatly improved the manuscript. Many thanks to Georgina Thurgate who

320 acted as NIEA Client Officer. 


\section{REFERENCES}

Allendorf, F.W. \& Luikart, G. (2007) Conservation and the Genetics of Populations, Oxford: Blackwell.

Bálint, M., Domisch, S., Engelhardt, C.H.M., Haase, P., Lehrian, S., Sauer, J., Theissinger, K., Pauls, S.U. \& Nowak, C. (2011) Cryptic biodiversity loss linked to global climate change. Nature Climate Change 1, 313-318.

Beatty, G.E. \& Provan, J. (2011) Comparative phylogeography of two related plant species with overlapping ranges in Europe, and the potential effects of climate change on their intraspecific genetic diversity. BMC Evolutionary Biology 11, 29.

Earl, D.A. \& vonHoldt, B.M. (2012) STRUCTURE HARVESTER: a website and program for visualizing STRUCTURE output and implementing the Evanno method. Conservation Genetics Resources 4, 359-361.

334 Edmands, S. (2007) Between a rock and a hard place: evaluating the relative risks of inbreeding and outbreeding for conservation and management. Molecular Ecology 16, 463-475.

Elith, J. \& Graham, C. H. (2009) Do they? How do they? WHY do they differ? On finding reasons for differing performances of species distribution models. Ecography 32, 66-77.

Evanno, G., Regnaud, S. \& Goudet, J. (2005) Detecting the number of clusters of individuals using the software STRUCTURE: a simulation study. Molecular Ecology

14, 2611-2620.

341 Farren A, Prodöhl, P. A., Laming, P. Reid N. (2010) Distribution of the common lizard

342 (Zootoca vivipara) and landscape favourability for the species in Northern Ireland. Amphibia-Reptilia, 31, 387-394. 
344 Hedberg, K.O. (1992) Taxonomic differentiation in Saxifraga hirculus L. (Saxifragaceae) - a

345 circumpolar Arctic-Boreal species of Central-Asiatic origin. Botanical Journal of the

$346 \quad$ Linnean Society 109, 377-393.

347 Hollingsworth, P. M., Tebbitt, M, Watson, K.J. \& Gornall, R.J. (1998) Conservation genetics

348 of an arctic species, Saxifraga rivularis L., in Britain. Botanical Journal of the Linnean

$349 \quad$ Society 128, 1-14.

350 Jackson, J.A., Laikre, L., Baker, C.S. \& Kendall, K.C. (2012) Guidelines for collecting and

351 maintaining archives for genetic monitoring. Conservation Genetics Resources 4, 527-

352536.

353 Jost, L. (2006) Entropy and diversity. Oikos 113, 363-375.

354 Kertland, M.P.H. (1956) Subularia aquatic and Saxifraga hirculus in Co. Antrim. Irish $355 \quad$ Naturalists' Journal 12, 51-52.

356 Leonard, J.A. (2008) Ancient DNA: applications for wildlife conservation. Molecular $357 \quad$ Ecology 17, 4186-4196.

358 Lesica, P. \& Allendorf, F.W. (1999) Ecological genetics and the restoration of plant 359 communities: mix or match? Restoration Ecology 7, 42-50.

360 Liu, C., Berry, P. M., Dawson, T. P. \& Pearson, R. G. (2005) Selecting thresholds of

361 occurrence in the prediction of species distributions. Ecography, 28, 385-393.

362 Mace, G.M. \& Purvis, A. (2008) Evolutionary biology and practical conservation: bridging a 363 widening gap. Molecular Ecology 17, 9-19.

364 Olesen, J.M. \& Warncke, E. (1989) Flowering and seasonal changes in flower sex ratio and 365 frequency of flower visitors in a population of Saxifraga hirculus. Holarctic Ecology 12, $366 \quad 21-30$. 
367 Olesen, J.M. \& Warncke, E. (1990) Morphological, phenological and biochemical

368 differentiation in relation to gene flow in a population of Saxifraga hirculus. Sommerfeltia

$369 \quad \mathbf{1 1}, 159-171$.

370 Oliver, C., Hollingsworth, P.M. \& Gornall, R.J. (2006) Chloroplast DNA phylogeography of 371 the arctic-montane species Saxifraga hirculus (Saxifragaceae). Heredity 96, 222-231.

372 Phillips, S. J., Anderson, R. P. \& Schapire, R. E. (2006) Maximum entropy modeling of 373 species geographic distributions. Ecological Modelling, 190, 231-259.

374 Phillips, S. J. \& Dudík, M. (2008) Modelling of species distributions with Maxent: new 375 extensions and a comprehensive evaluation. Ecography, 31, 161-175.

376 Pritchard, J.K., Stephens, M. \& Donnelly, P. (2000) Inference of population structure using 377 multilocus genotype data. Genetics 155, 945-959.

378 Provan, J. \& Wilson, P.J. (2007) Development of microsatellites for the peat moss Sphagnum 379 capillifolium using ISSR cloning. Molecular Ecology Notes 7, 254-256.

380 Provan, J. \& Maggs, C.A. (2012) Unique genetic variation at a species' rear edge is under 381 threat from global climate change. Proceedings of the Royal Society of London Series B $382 \quad 279,39-47$.

383 Schwartz, M.K., Luikart, G. \& Waples, R.S. (2007) Genetic monitoring as a promising tool 384 for conservation and management. Trends in Ecology and Evolution 22, 25-33.

385 Vittoz, P., Wyss, T. \& Gobat, J-M. (2006) Ecological conditions for Saxifraga hirculus in 386 Central Europe: a better understanding for a good protection. Biological Conservation $387 \quad$ 131, 594-608.

388 Wandeler, P., Hoeck, P.A.E. \& Keller, L.F. (2007) Back to the future: museum specimens in 389 population genetics. Trends in Ecology and Evolution 22, 634-642. 
390 Warncke, E., Terndrup, U., Michelsen, V. \& Erhardt, A. (1993) Flower visitors to Saxifraga 391 hirculus in Switzerland and Denmark, a comparative study. Botanica Helvetica 103, 141$392 \quad 147$.

393 Welch, D. (2002) The establishment of recovery sites for Saxifraga hirculus L. in NE 394 Scotland. Botanical Journal of Scotland 54, 75-88. 


\section{SUPPORTING INFORMATION}

Additional supporting information may be found in the online version of this article:

Table S1 Herbarium codes of samples used.

Table S2 Description of variables used to describe landscape suitability for the Yellow marsh saxifrage.

Figure S1 Jackknife analyses of the importance of environmental variables in maximum entropy modelling of yellow marsh saxifrage distribution.

Figure S2 Marginal response curves of the predicted probability of yellow marsh saxifrage occurrence for each explanatory variable that contributed to $95 \%$ of the cumulative variance. 


\section{BIOSKETCHES}

Gemma Beatty is a Postdoctoral Research Fellow at Queen's University Belfast. Her PhD research compared how postglacial recolonization and range-edge effects have shaped the genetic diversity of several Monotropoideae species. She is interested in using genetic approaches to study the effects of past and present climate change on the distribution ranges of natural populations, and the various factors that determine these ranges.

Neil Reid is Manager of Quercus, Northern Ireland's Centre for Biodiversity and Conservation Biology. Has has a background in species distribution modelling as a tool for identifying high conservation value areas for endangered species.

Jim Provan is a Reader in Evolutionary Genetics at Queen's University Belfast. His research interests focus on how genetic variation is distributed across species ranges, and on the effects of past, present and future climate change on levels and patterns of intraspecific diversity.

Author contributions: N.R. and J.P. conceived the study; G.E.B. and J.P. collected the data; All three authors carried out the analyses and wrote the manuscript. 
Table 1 Details of populations analysed in the present study. $N$-number of individuals studied; $A$-number of alleles; $H_{O}$ - observed heterozygosity; $H$ - phenotype diversity (GiniSimpson index).

\begin{tabular}{|c|c|c|c|c|c|c|c|c|c|}
\hline County & Population & Year & Code & Lat & Long & $N$ & $A^{\mathrm{a}}$ & $H_{O}{ }^{\mathrm{a}}$ & $H^{\mathrm{a}}$ \\
\hline \multirow[t]{13}{*}{ Co. Antrim } & \multirow[t]{8}{*}{ Garron Plateau } & 1886 & GAR-1886 & 54.990 & -6.096 & 5 & 18 & 0.600 & 0.768 \\
\hline & & 1889 & GAR-1889 & & & 2 & N/A & N/A & N/A \\
\hline & & 1914 & GAR-1914 & & & 3 & N/A & N/A & N/A \\
\hline & & 1920 & GAR-1920 & & & 2 & N/A & N/A & N/A \\
\hline & & 1922 & GAR-1922 & & & 2 & N/A & N/A & N/A \\
\hline & & 1955 & GAR-1955 & & & 8 & 23 & 0.417 & 0.649 \\
\hline & & 1957 & GAR-1957 & & & 2 & $\mathrm{~N} / \mathrm{A}$ & N/A & N/A \\
\hline & & 2011 & GAR-2011 & & & 13 & 19 & 0.459 & 0.445 \\
\hline & \multirow[t]{5}{*}{ Rasharkin ${ }^{\mathrm{b}}$} & 1837 & RAS-1837 & 54.9 & -6.4 & 10 & 27 & 0.533 & 0.735 \\
\hline & & 1853 & RAS-1853 & & & 2 & N/A & N/A & N/A \\
\hline & & 1857 & RAS-1857 & & & 6 & 23 & 0.556 & 0.767 \\
\hline & & 1873 & RAS-1873 & & & 5 & 19 & 0.500 & 0.750 \\
\hline & & 1884 & RAS-1884 & & & 6 & 20 & 0.389 & 0.711 \\
\hline Co. Derry & Coleraine $^{b}$ & $1800 \mathrm{~s}$ & COL-18XX & 55.1 & -6.7 & 7 & 20 & 0.572 & 0.698 \\
\hline \multirow[t]{18}{*}{ Co. Mayo } & \multirow[t]{2}{*}{ Largan Mor } & \multirow[t]{2}{*}{2011} & LMA-2011 & 54.140 & -9.694 & 24 & 28 & 0.743 & 0.581 \\
\hline & & & LMB-2011 & 54.154 & -9.686 & 24 & 27 & 0.750 & 0.643 \\
\hline & \multirow[t]{4}{*}{ Sheean } & \multirow[t]{4}{*}{2011} & SHA-2011 & 54.118 & -9.653 & 24 & 26 & 0.660 & 0.630 \\
\hline & & & SHB-2011 & 54.119 & -9.652 & 24 & 30 & 0.882 & 0.790 \\
\hline & & & SHC-2011 & 54.117 & -9.656 & 24 & 27 & 0.812 & 0.699 \\
\hline & & & SHD-2011 & 54.119 & -9.651 & 18 & 25 & 0.759 & 0.770 \\
\hline & Uggoll & 2011 & UGG-2011 & 54.108 & -9.644 & 24 & 25 & 0.778 & 0.512 \\
\hline & Barroosky & 2011 & BAR-2011 & 54.195 & -9.631 & 24 & 30 & 0.785 & 0.808 \\
\hline & \multirow[t]{2}{*}{ Sheskin } & \multirow[t]{2}{*}{2011} & SKA-2011 & 54.201 & -9.562 & 24 & 23 & 0.549 & 0.673 \\
\hline & & & SKB-2011 & 54.198 & -9.557 & 24 & 23 & 0.500 & 0.619 \\
\hline & Croaghaun & 2011 & CRO-2011 & 54.182 & -9.469 & 24 & 26 & 0.708 & 0.664 \\
\hline & Formoyle & 2011 & FOR-2011 & 54.141 & -9.448 & 24 & 22 & 0.840 & 0.560 \\
\hline & Aghoo & 2011 & AGH-2011 & 54.257 & -9.408 & 24 & 32 & 0.729 & 0.764 \\
\hline & \multirow[t]{5}{*}{ Bellacorick } & 1857 & BEL-1857 & 54.2 & -9.5 & 11 & 25 & 0.576 & 0.703 \\
\hline & & 1858 & BEL-1858 & & & 13 & 27 & 0.615 & 0.712 \\
\hline & & 1965 & BEL-1965 & & & 3 & N/A & N/A & N/A \\
\hline & & 1968 & BEL-1968 & & & 6 & 19 & 0.750 & 0.821 \\
\hline & & 1970 & BEL-1970 & & & 3 & $\mathrm{~N} / \mathrm{A}$ & N/A & N/A \\
\hline \multirow[t]{2}{*}{ Co. Westmeath } & \multirow[t]{2}{*}{ Lisclogher ${ }^{b}$} & 1880 & LIS-1880 & 53.6 & -7.1 & 3 & N/A & N/A & N/A \\
\hline & & 1888 & LIS-1888 & & & 4 & N/A & N/A & N/A \\
\hline
\end{tabular}

${ }^{\mathrm{a}}$ Number of alleles, observed heterozygosity and phenotype diversity only calculated for samples with $N \geq 5$

${ }^{\mathrm{b}}$ Extinct population: Latitude / Longitude approximate 
Table $2 S$. hirculus nuclear microsatellite primers used in this study. A - number of alleles.

\begin{tabular}{|c|c|c|c|c|}
\hline Locus & Repeat & Primers & $\mathrm{A}$ & Allele size range \\
\hline \multirow[t]{2}{*}{ SH-1-B08 } & $(\mathrm{AGC})_{5}$ & CCCGCCATTTCTCTATACCA & 7 & $119-137$ \\
\hline & & GGTTGAGCCAGTCCAAGAAG & & \\
\hline \multirow[t]{2}{*}{ SH-2-D03 } & $(\mathrm{CTA})_{5}$ & GCTTTTCCATTTTTAGGGCTTT & 10 & $139-169$ \\
\hline & & AAAAGGAAAGTGAGATACTAATTAGAACAG & & \\
\hline \multirow[t]{2}{*}{ SH-3-A03 } & $(\mathrm{AT})_{6}$ & TCAAAATATTATTAAGGGAAAAATTCTCA & 8 & $156-188$ \\
\hline & & CCAAATGTTTGAGTTATGTATAGTTACG & & \\
\hline \multirow[t]{2}{*}{ SH-3-B11 } & $(\mathrm{TCTT})_{7}$ & TGGCTACTACAATGTAAAGTTGTCTC & 8 & $132-160$ \\
\hline & & CATAAGTCAAAAGTCAAGGTGTCG & & \\
\hline \multirow[t]{2}{*}{ SH-4-E03 } & $(\mathrm{AAAT})_{4}$ & TGTCTGTTTGGACATTCCCTTA & 11 & $136-208$ \\
\hline & & TCAATATATTCTTAAGTTGATTATTAAGTGTG & & \\
\hline \multirow[t]{2}{*}{ SH-4-F10 } & $(\mathrm{TA})_{6}$ & GGATCCCTCACTTGAAGCTC & 16 & $122-160$ \\
\hline & & TGTATAGATCAACTCTGCCAAAAA & & \\
\hline
\end{tabular}

Forward tailed with CACGACGTTGTAAAACGAC

Reverse tailed with GTGTCTT 
Table 3 Mean levels of genetic diversity calculated over all individuals in the historical vs. extant samples from the Garron Plateau population. A - mean number of alleles; $H_{O}-$ mean observed heterozygosity; $H$ - mean phenotype diversity (Gini-Simpson index). Significance of differences in mean values was estimated using a t-test.

\begin{tabular}{lccc}
\hline \multirow{2}{*}{ Period } & \multicolumn{3}{c}{ Diversity } \\
\cline { 2 - 4 } & $A$ & $H o$ & $H$ \\
\hline Historical (pre-1958) & 1.732 & 0.507 & 0.710 \\
Extant & 1.722 & 0.459 & 0.445 \\
& NS & NS & $P=0.013$ \\
\hline
\end{tabular}




\section{Figure Legends}

Figure 1 Map showing locations of the populations analysed in the present study. Population codes correspond to those in Table 1. Codes in italics represent extinct populations. Locations of the RAS, COL, LIS and BEL populations are approximate.

Figure 2 Graph of $\Delta K$ values indicating the most likely number(s) of genetic clusters (After Evanno et al., 2005).

Figure 3 Results of the Bayesian clustering analysis performed using STRUCTURE (V2.3.3). Each column represents an individual, with the height of each coloured segment indicating the probability of membership to each of $K=4$ (top) or $K=8$ (middle) genetic clusters. Bottom shows enlarged assignment of Northern Ireland individuals for $K=8$.

Figure 4 Landscape suitability for the S. hirculus throughout Ireland showing areas of high quality (red) in Co. Mayo, and areas of lower quality (turquoise) in Northern Ireland, with areas in dark blue being totally unsuitable.

Figure S1 Jackknife analyses of the importance of environmental variables in maximum entropy modelling of yellow marsh saxifrage distribution. A heuristic estimate of the relative contribution of each variable to the global model is given in parentheses whilst variables are listed in descending order of importance. Grey bars show the performance of the global model (known as \% gain) without each variable and black bars show the influence of each variable in isolation (derived from a univariate model only). Percentage contributions that sum to $95 \%$ of variance are shown in bold.

Page $\mid 27$ 
Figure S2 Marginal response curves of the predicted probability of yellow marsh saxifrage occurrence for each explanatory variable that contributed to $95 \%$ of the cumulative variance. Curves show logistic predictions when all other environmental variables where maintained at their mean value. 


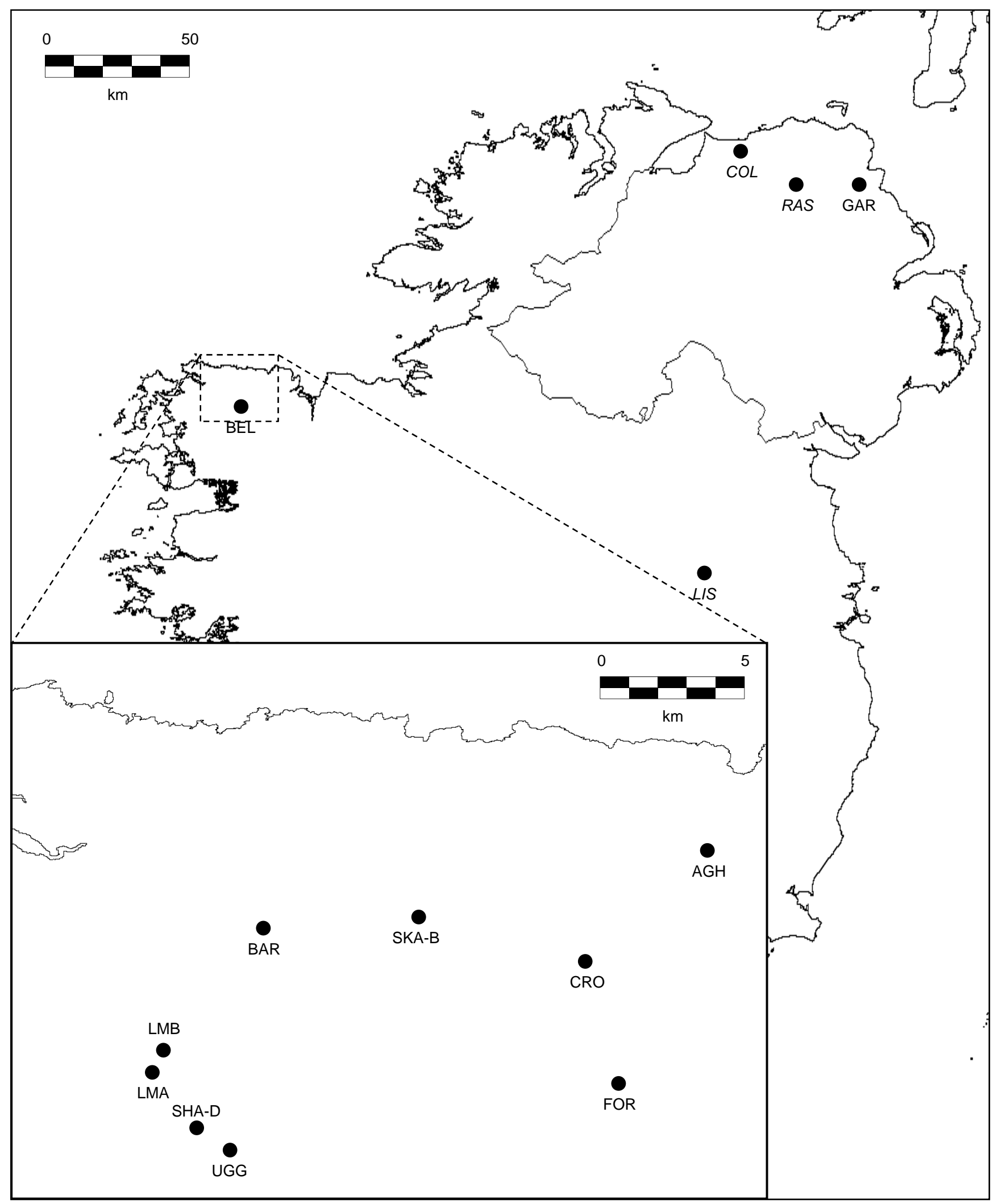




$$
\Lambda_{\Lambda}
$$




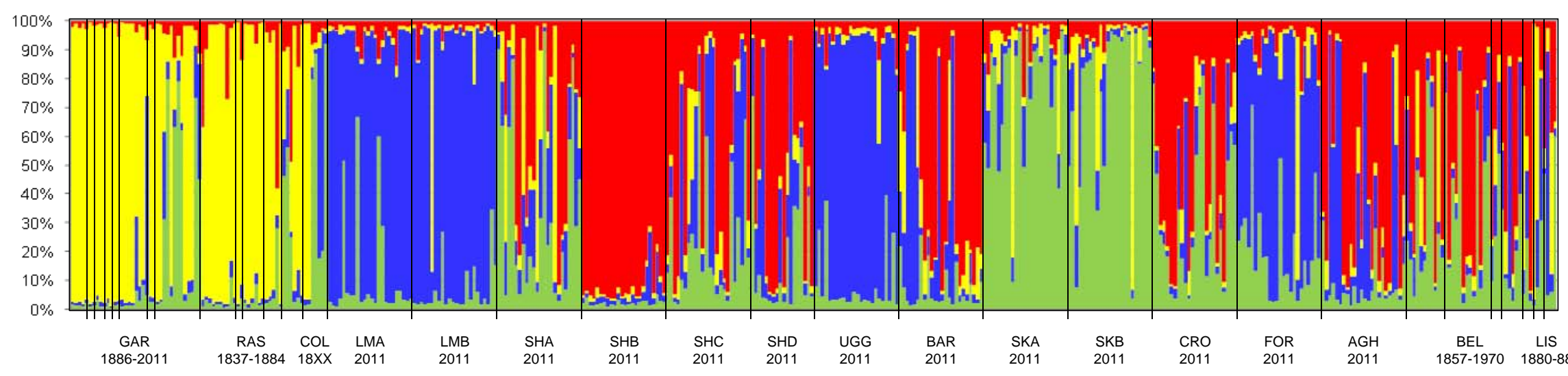

$K=4$

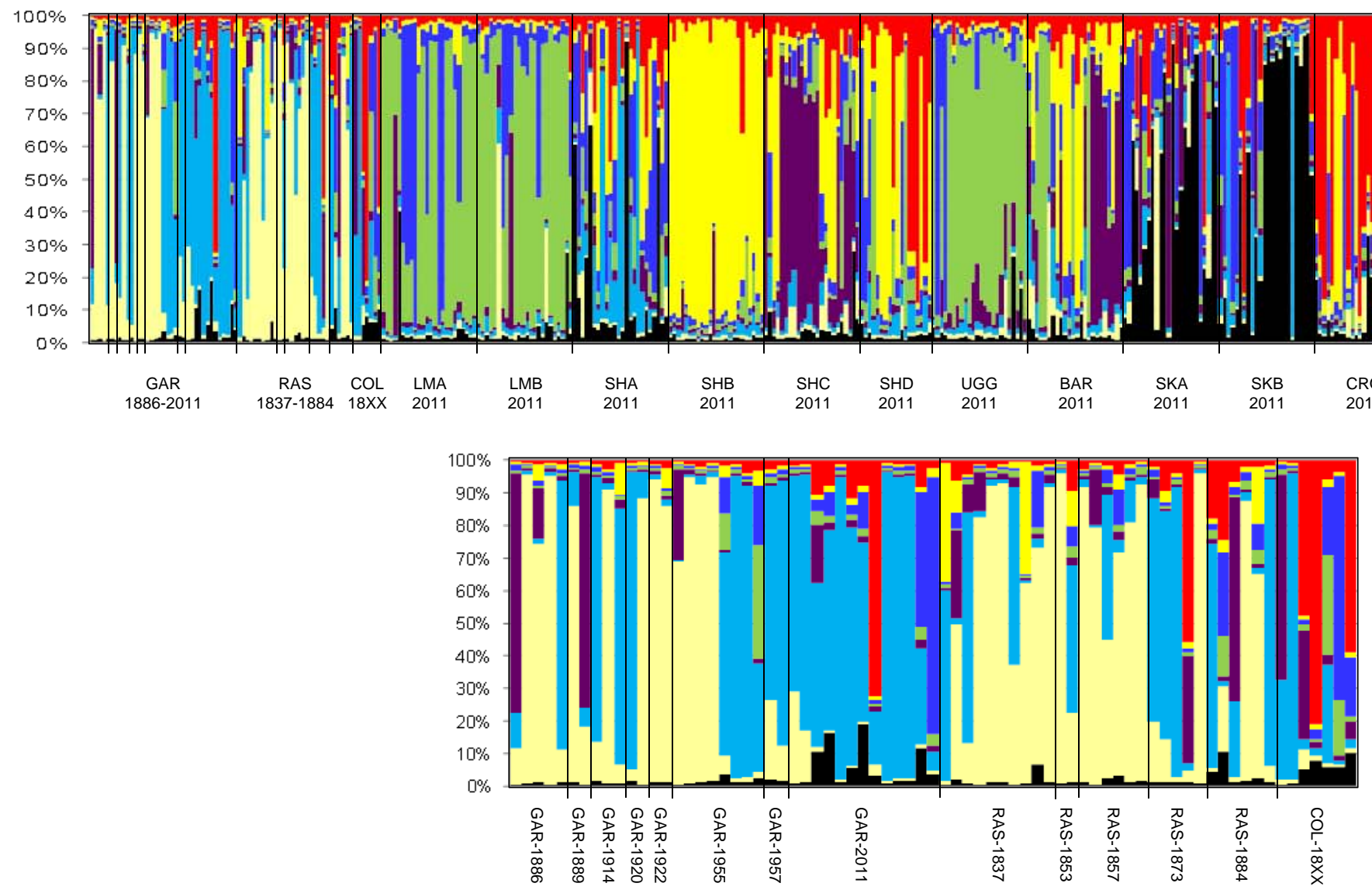




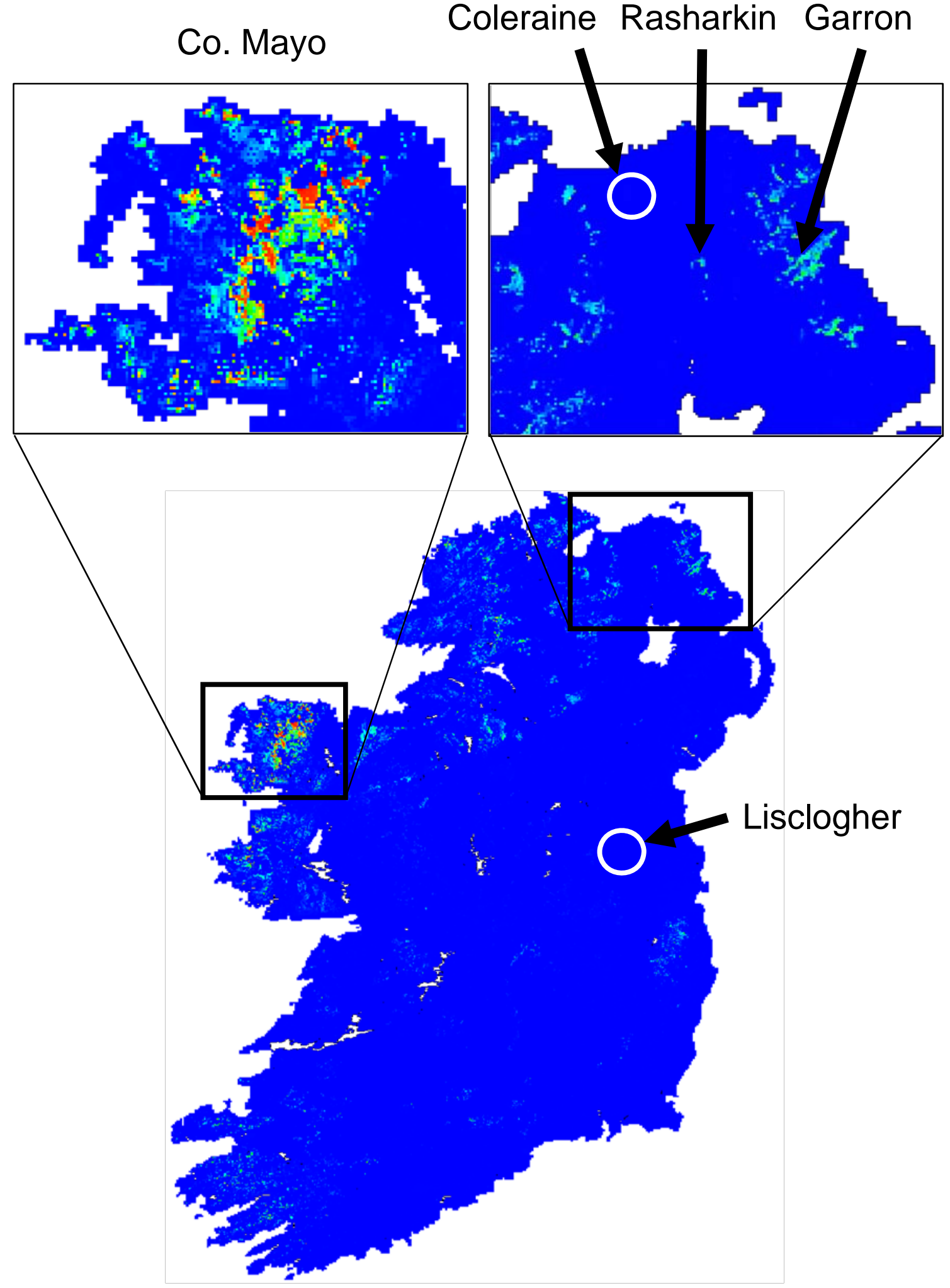


Table S1 Herbarium codes of samples used

\begin{tabular}{llc}
\hline Code & Herbarium & $N$ \\
\hline GAR-1886 & BEL-H61348 & 1 \\
& BEL-H61349 & 2 \\
& DBN-17-07-1886 & 2 \\
GAR-1889 & DBN-22-1967 & 2 \\
GAR-1914 & DBN- & 3 \\
GAR-1920 & BEL-H61347 & 2 \\
GAR-1922 & DBN- & 2 \\
GAR-1955 & BEL-H61345 & 4 \\
& DBN-4-1958 & 2 \\
& DBN-32-1980 & 2 \\
GAR-1957 & BEL-H61346 & 2 \\
RAS-1837 & DBN-DM- & 10 \\
RAS-1853 & DBN-003989 & 2 \\
RAS-1857 & DBN-94-Sh-1857 & 6 \\
RAS-1873 & DBN-Sh-97 & 5 \\
RAS-1884 & BEL-H917 & 6 \\
BEL-1957 & DBN-04001 & 5 \\
& DBN-3-10-1957 & 6 \\
BEL-1958 & DBN-004002 & 9 \\
& DBN-003999 & 4 \\
BEL-1965 & DBN-004003 & 3 \\
BEL-1968 & DBN-15-8-68 & 6 \\
BEL-1970 & DBN-003991 & 3 \\
LIS-1880 & DBN-631 & 3 \\
LIS-1888 & DBN-Sh-1888 & 4 \\
\hline
\end{tabular}


Table S2 Description of variables used to describe landscape suitability for the Yellow marsh saxifrage

\begin{tabular}{|c|c|c|}
\hline Name & Units & Description \\
\hline \multicolumn{3}{|l|}{ Topography } \\
\hline Altitude & $\mathrm{m}$ & Elevation above sea level in metres \\
\hline Hilliness & $\mathrm{m}$ & Standard deviation in mean elevation above sea level in metres per 500m cell \\
\hline \multicolumn{3}{|l|}{ Habitat composition } \\
\hline Bog, fen, marsh \& swamp & \% cover & Coverage representing a composite of Bog, fen, marsh \& swamp derived from CORINE 2000 \\
\hline Pasture & \% cover & Coverage of pasture derived from CORINE 2000 \\
\hline Coniferous plantations & $\%$ cover & Coverage of coniferous woodland derived from CORINE 2000 \\
\hline Natural grass & \% cover & Coverage of natural grass derived from CORINE 2000 \\
\hline Scrub & \% cover & Coverage of scrub derived from CORINE 2000 \\
\hline Riparian corridor & $\mathrm{Km}$ & Total length of river and water body edge including lakes, reservoirs, ponds, rivers, streams and canals in metres \\
\hline Standing freshwater & \% cover & Coverage of lakeland derived from CORINE 2000 \\
\hline \multicolumn{3}{|l|}{ Climate } \\
\hline Tempmin & ${ }^{\circ} \mathrm{C}$ & Minimum temperature of the coldest month \\
\hline Temp $_{\max }$ & ${ }^{\circ} \mathrm{C}$ & Maximum temperature of the warmest month \\
\hline Precipitation $_{\text {annual }}$ & $\mathrm{mm}$ & Total annual precipitation \\
\hline Seasonality & Index & Standard deviation of mean monthly temperatures $* 100$ \\
\hline
\end{tabular}




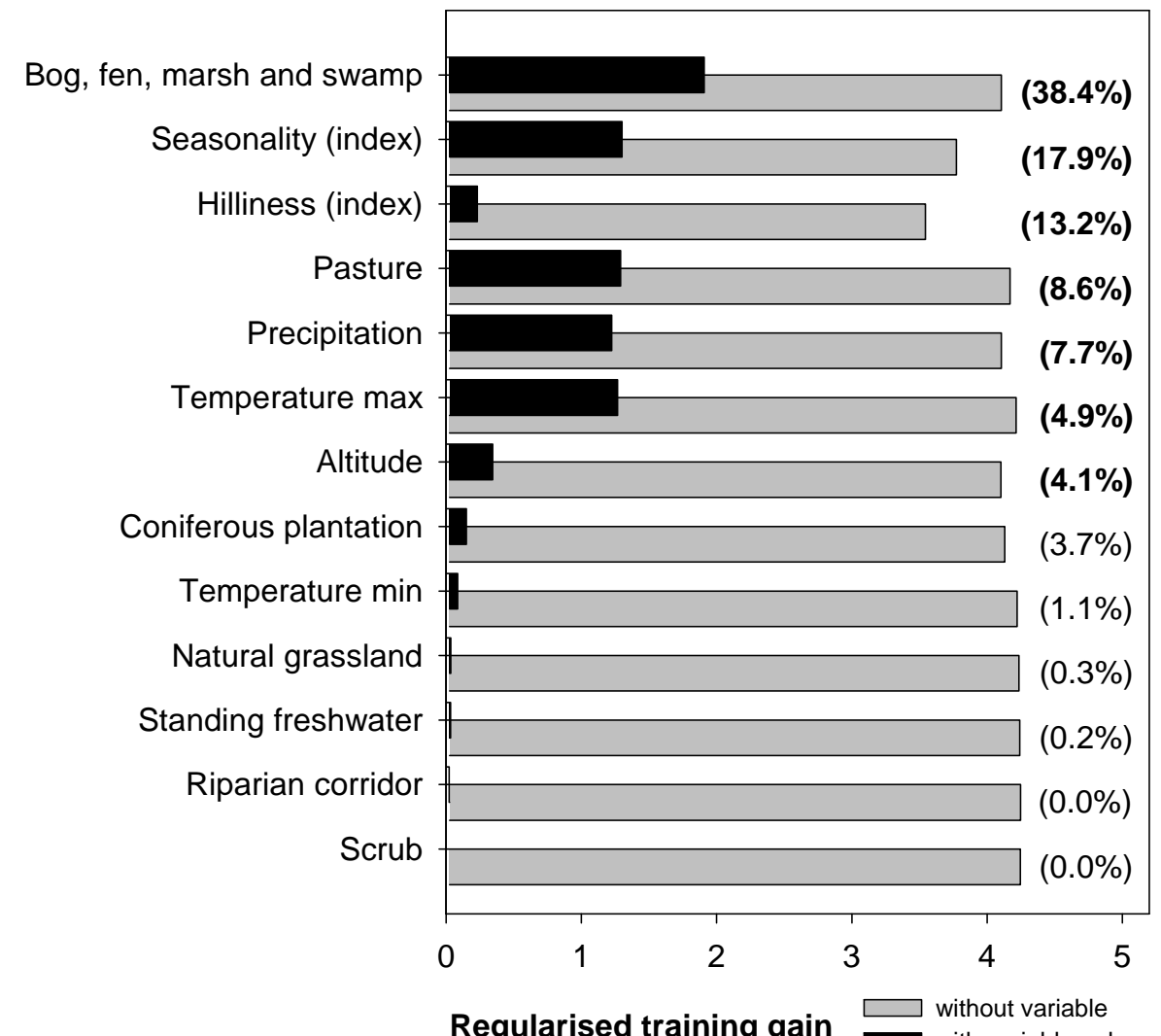

Regularised training gain $\square$ without variable 

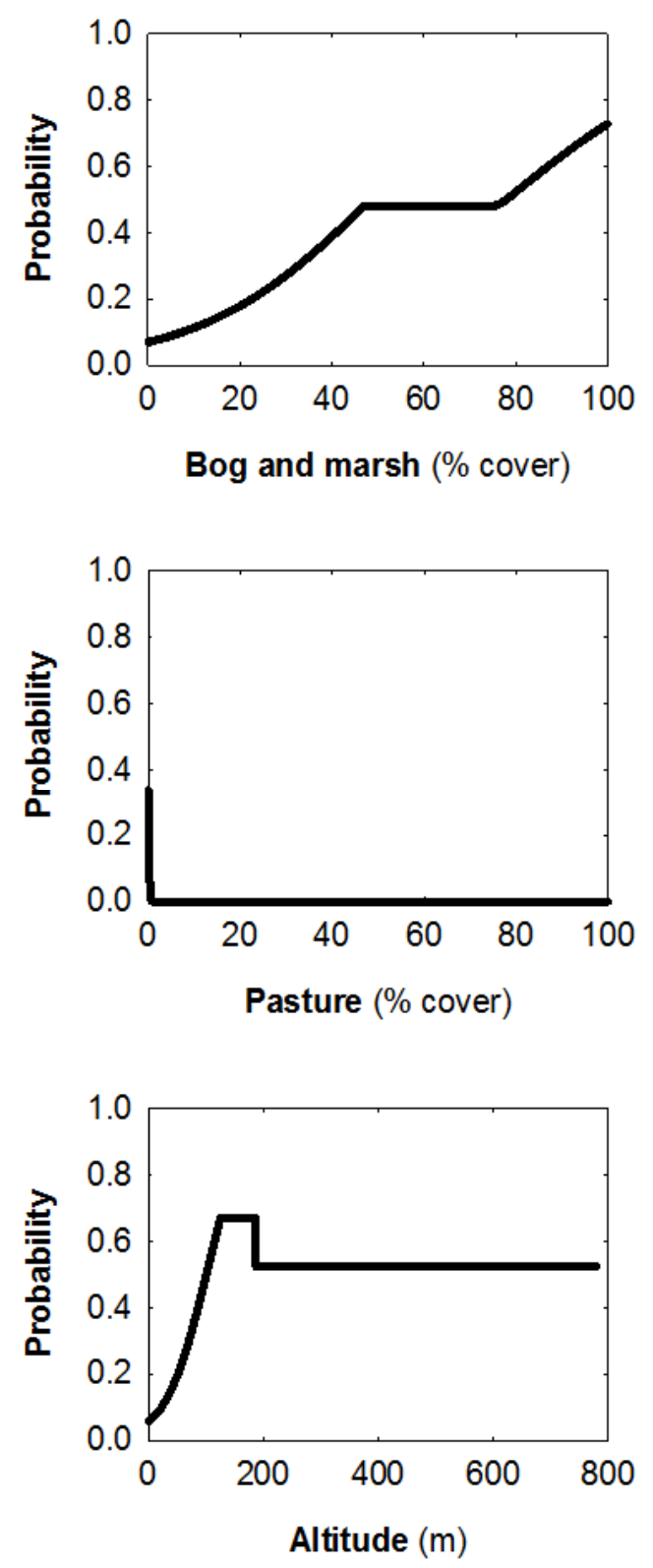
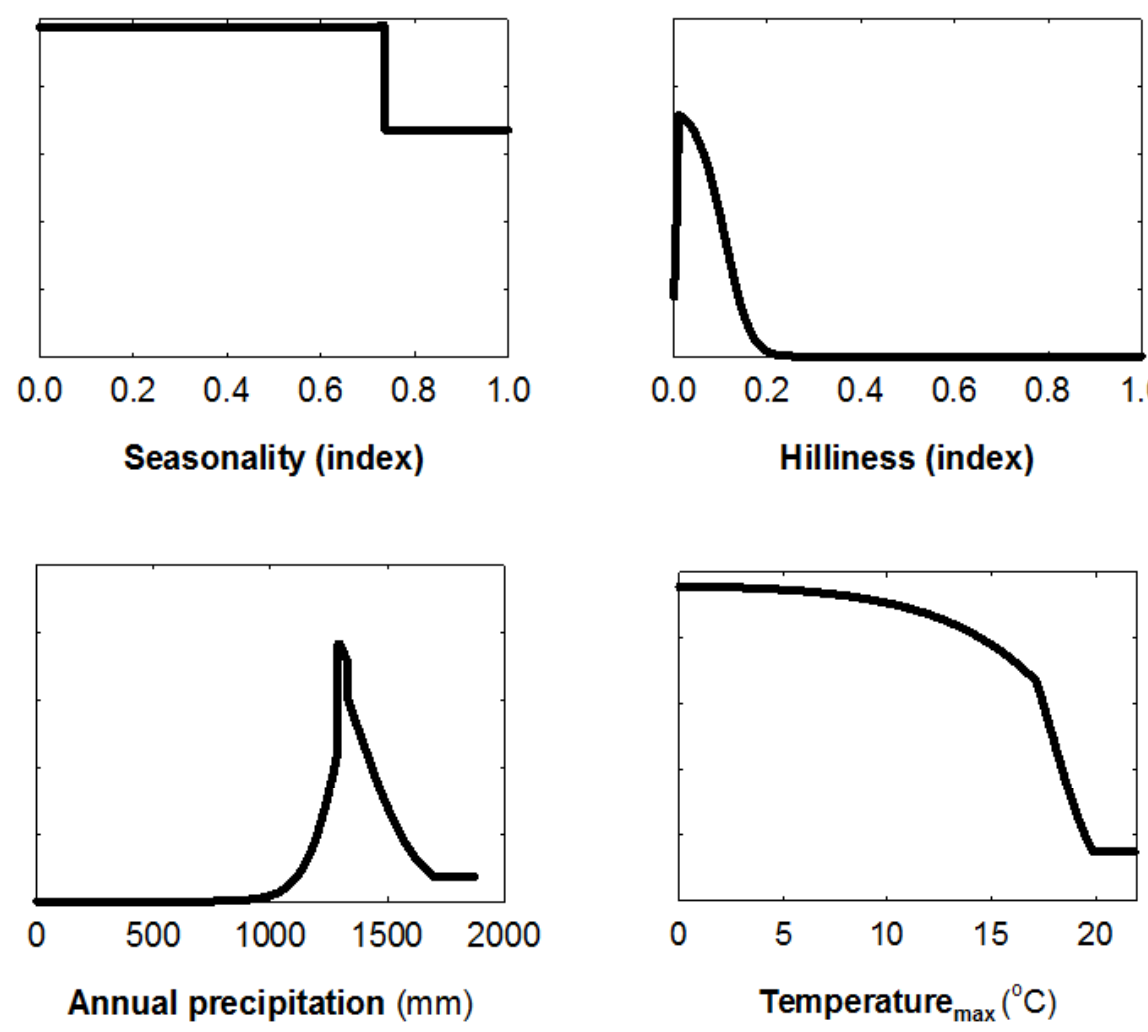